\title{
Detecting second mesiobuccal canal in maxillary \\ first molars in Erbil citizens: CBCT
}

\author{
Retrospective study
}

\author{
Mustafa T. Mohamadamin ${ }^{(1)}$; Karam A. Thiab ${ }^{(2)}$; Ribwar F. Khalid ${ }^{(3)}$ Khidir M. Khidir $^{(4)}$
}

\begin{abstract}
Background and Objectives: The success of root canal therapy is depending on cleaning and shaping of the root canals. The root canals have complex morphology and wide individual variations. The purpose of this study was to investigate the prevalence of second mesiobuccal canal (MB2) of maxillary first molars in Erbil population using cone beam computed tomography (CBCT).
\end{abstract}

Materials and Methods: A total of 101 permanent maxillary first molars were randomly selected from Erbil citizens. All teeth were examined for the number of root canals and the presence of second mesiobuccal canal by Cone Beam Computed Tomography (CBCT).

Result: The MB2 canal was found in $80.2 \%$ (the $95 \% \mathrm{Cl}$ is $72.3 \%$ to $87.1 \%$ ) of the analyzed cases (81/101).

Conclusion: The second mesiobuccal canal was found in a high percentage of the samples. And it is within normal magnitude in comparison with the common findings in the literature. These results indicate that $\mathrm{CBCT}$ is an effective, high-precision diagnostic tool for detecting canals.

Keywords: Maxillary first molars, second mesiobuccal canal, cone beam computed tomography, Erbil Citizens.

\footnotetext{
${ }^{(1)}$ Faculty of Dentistry- Tishk International University

${ }^{(2)}$ Faculty of Dentistry- Tishk International University

${ }^{(3)}$ Faculty of Dentistry- Tishk International University

${ }^{(4)}$ Khanzad Specialized Dental Center, Erbil Health Department
}

\section{Introduction}

Knowing the proper root canal morphology is very important to avoid failures of root canal treatment. ${ }^{1}$ Therefore, clinicians should recognize and have knowledge about the common root canal morphologies and possible anatomic variations. The clinician should be aware of the possibility of having additional canals in order to minimize the risk of treatment failure. ${ }^{2,3}$ The internal complexities of root canals are genetically determined and carry definitive importance in anthropology., The root canal anatomical variations due to genetic and ethnic differences have been discussed in many studies. ${ }^{6,7}$ The major cause of root canal therapy failure when treating the first maxillary molar is failure to debride the entire root canal system, which usually occurs because the clinician was unable to detect additional root canals. ${ }^{8}$ It was reported that remnants of pulp tissue can be a reservoir for the growth of microorganisms, which may affect and compromise treatment outcomes. ${ }^{9}$ Many studies investigated the morphology of the maxillary permanent molars focusing on the presence of a second mesiobuccal root canal in the mesial root. ${ }^{10-12}$ They reported varying prevalence of the second mesiobuccal canal of maxillary first molars. According to a study by Pomeranz and Fishelberg, clinicians are aware that the mesiobuccal root often contains two canals. ${ }^{13}$ However, the second canal (MB2) is often not observed. ${ }^{14}$ Therefore, the ability to locate all canals in the 
root canal system is one of the deciders about the success rate of the root canal therapy. Maxillary molars often have two canals in the mesiobuccal root, as described by Hess in $1925 .{ }^{15}$ In 1969, Wieneet al., suggested that the inability to locate, instrument, and obturate the MB2 canal could lead to endodontic failure. ${ }^{2}$ The anatomy of the roots of the maxillary first molars is very complex. ${ }^{16}$ Locating the MB2 canal is thus a challenge for the clinician in achieving successful treatment of maxillary molars (Figure 1). If the prevalence of the MB2 is high in a population, time should be devoted to its location and treatment. ${ }^{17}$

The aim of this current study was to determine the prevalence of MB2 in 101 samples of Erbil citizens using CBCT. In addition, we investigated the number of roots in maxillary first molars. The data obtained from this study will give information about the number of roots and canals in the permanent maxillary first molar in Erbil population. Which may help the clinician to increase the success rate of root canal treatment of maxillary first molars.

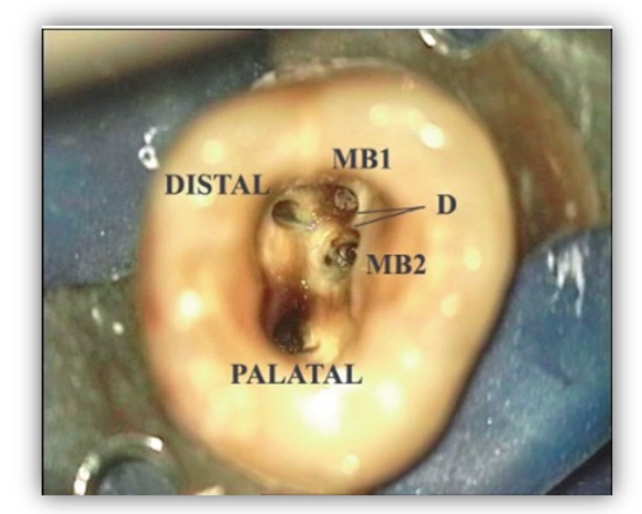

Figure 1: Occlusal view of maxillary first molar with MB1 and MB2. D=distance between MB1 and MB2. $^{18}$

\section{Materials and methods}

A total of 101 samples of CBCT scans of maxillary first molars (right or left) from 101 patients were collected from archives of Smart center, Swe Dent, Hollywood Smile Studio and Denta+ private radiographic centers in Erbil city. CBCT images were from Erbil citizens who had CBCT examination as part of their dental examination, diagnosis or treatment planning during the years (Jan. 2015 - Dec. 2017). And access to information regarding age and gender was provided. Which from 101 patients 31 of them were males $(30.7 \%)$ and 70 of them were females $(69.3 \%)$. And their age was between 12-56 years old.

The CBCT images were selected for enrollment in this investigation based on the following criteria:

Maxillary first molars with complete root formation.

Intact roots without fractures or cracks.

Maxillary permanent molars without periapical lesions.

No present of metallic restoration.

No previous root canal treatment.

No posts or crown restorations.

No External or Internal Root resorption.

No evidence of periapical surgery.

No canal calcification.

No any developmental anomalies.

CBCT images of good quality and without any artifacts. ${ }^{19,20}$

The CBCT images were taken using NewTomVGi (QR SRL Company, Verona, Italy) with the following parameters: $8 \times 11$ $\mathrm{cm}$ field of view (FOV), $200 \mu \mathrm{m}$ voxel size, and $110 \mathrm{kVp}$ and exposure time of $3.6 \mathrm{~s}$. (The machine was same in all four centers). The CBCT images were analyzed with NNT Viewer. Serial axial, coronal, and sagittal views of CBCT images were examined by carefully rolling the toolbar from the pulp chamber to the apex until an agreed diagnosis was reached for each case. The number of roots and number of canals with the presence of second mesiobuccal canal were recorded in each right or left maxillary first molars. Descriptive statistics (age and gender) were also recorded. The examiners had the ability to magnify the images, and change the viewing settings, such as density, contrast and sharpness, in order to enhance visibility and identification of the examined structures. CBCT samples presented with three canals, four canals and five canals as it is shown in figures 2, 3 and 4. The number of CBCT scans of Erbil 


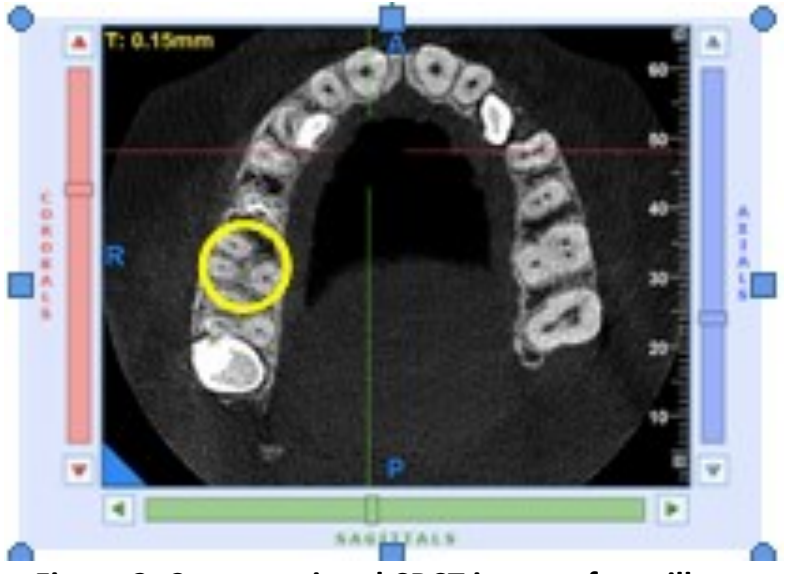

Figure 2: Cross-sectional CBCT image of maxillary right first molar with three separate roots and three canals (yellow circle). (Hollywood Smile Studio)

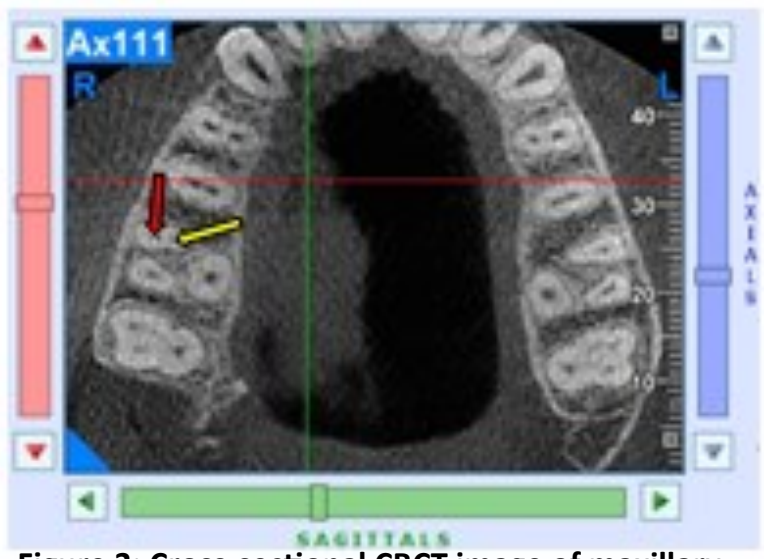

Figure 3: Cross-sectional CBCT image of maxillary first molar with a clearly distinguished MB2 canal (yellow arrows). The red arrows denote the mesiobuccal root in the maxillary first molar. (Smart Center)

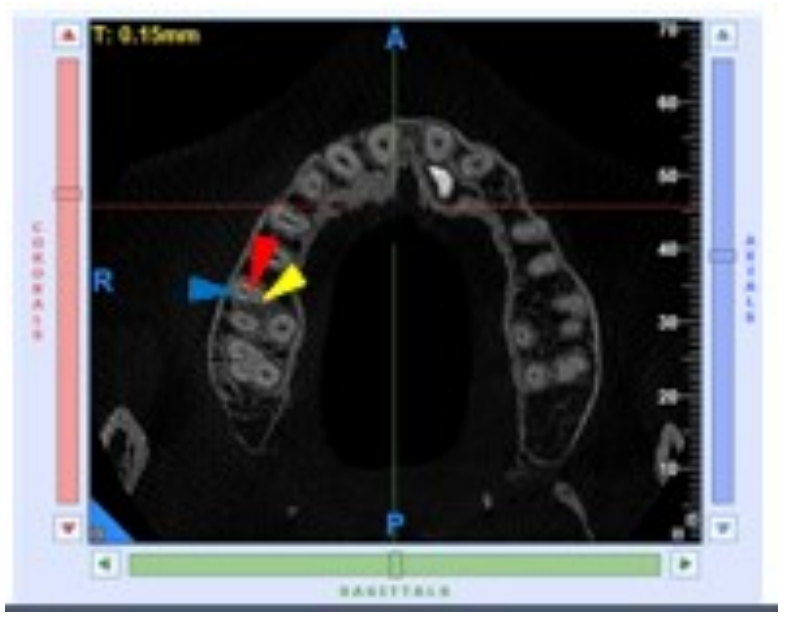

Figure 4: Cross-sectional CBCT image of maxillary right first molar with three canals in mesiobuccal root. MB1 (blue triangle), MB2 (red triangle), MB3 (yellow triangle). (Swe Dent) individuals with second mesiobuccal canal in maxillary first molars was 81 from 101 CBCT samples, thus the prevalence of the second mesiobuccal canal was analyzed.

Statistical analysis. Data were analyzed using the Statistical Package for Social Sciences (SPSS, version 22). Chi square test of association was used to compare proportions. Fisher's exact test was used when the expected count of more than $20 \%$ of the cells of the table was less than 5. A p value of $\leq 0.05$ was considered statistically significant.

\section{Results}

The total number of the participants was 101 patients. Their mean age \pm SD was $26.22 \pm 8.03$ years, ranging from 12 to 56 years. The median was 26 years. Table 1 shows that the highest proportion of patients aged 20-29 years, and only 5\% aged $\geq 40$ years. The majority $(69.3 \%)$ of the sample were females. The table shows that almost all of the patients $(99 \%)$ had three roots, and only one patient had four roots. Regarding the number of the canals, the table shows that the majority $(70.3 \%)$ had four canals, $19.8 \%$ had three canals, and $9.9 \%$ had five canals. The fifth canal located to the mesiobuccal side of the tooth thus we identified as third mesiobuccal canal (MB3). Which is coincide with the common findings that have been recorded previously in other literature from different citizens.

Table 1. Basic characteristics of the study sample.

\begin{tabular}{|c|c|c|}
\hline Age (years) & No. & (\%) \\
\hline$<20$ & 24 & $(23.8)$ \\
\hline $20-29$ & 41 & $(40.6)$ \\
\hline $30-39$ & 31 & $(30.7)$ \\
\hline$\geq 40$ & 5 & $(5.0)$ \\
\hline Gender & No. & (\%) \\
\hline Male & 31 & $(30.7)$ \\
\hline Female & 70 & $(69.3)$ \\
\hline No. of roots & No. & $(\%)$ \\
\hline Three & 100 & $(99.0)$ \\
\hline Four & 1 & $(1.0)$ \\
\hline No. of canals & No. & $(\%)$ \\
\hline Three & 20 & $(19.8)$ \\
\hline Four & 71 & $(70.3)$ \\
\hline Five & 10 & $(9.9)$ \\
\hline Total & 101 & $(100.0)$ \\
\hline
\end{tabular}


Table 2: Prevalence of MB2 by age and gender.

\begin{tabular}{|c|c|c|c|c|c|c|c|}
\hline & \multicolumn{6}{|c|}{ Prevalence of MB2 } & \multirow{3}{*}{$\mathbf{p}$} \\
\hline & \multicolumn{2}{|c|}{ No. } & \multicolumn{2}{|c|}{ Yes } & \multicolumn{2}{|c|}{ Total } & \\
\hline & No. & $(\%)$ & No. & (\%) & No. & (\%) & \\
\hline \multicolumn{7}{|c|}{ Age (years) } & \multirow{5}{*}{$>0.999 *$} \\
\hline$<20$ & 5 & $(20.8)$ & 19 & $(79.2)$ & 24 & $(100.0)$ & \\
\hline $20-29$ & 8 & $(19.5)$ & 33 & $(80.5)$ & 41 & $(100.0)$ & \\
\hline $30-39$ & 6 & $(19.4)$ & 25 & $(80.6)$ & 31 & $(100.0)$ & \\
\hline$\geq 40$ & 1 & $(20.0)$ & 4 & $(80.0)$ & 5 & $(100.0)$ & \\
\hline \multicolumn{7}{|l|}{ Gender } & \multirow{3}{*}{0.974} \\
\hline Male & 6 & $(20.0)$ & 24 & $(80.0)$ & 31 & $(100.0)$ & \\
\hline Female & 14 & (19.7) & 57 & $(80.3)$ & 70 & $(100.0)$ & \\
\hline Total & 20 & $(19.8)$ & 81 & (80.2) & 101 & (100.0) & \\
\hline
\end{tabular}

*By Fisher's exact test.

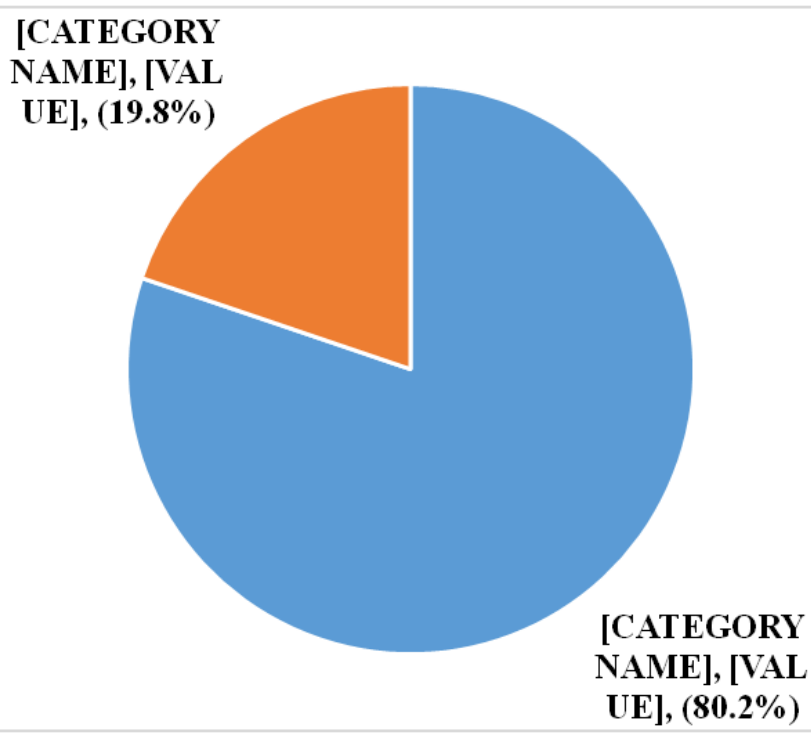

Figure 5. Prevalence of MB2.

Table 3: Number of canals by number of roots.

\begin{tabular}{|c|c|c|c|c|c|c|c|}
\hline \multirow{3}{*}{ No. of canals } & \multicolumn{4}{|c|}{ No. of roots } & & & \\
\hline & \multicolumn{2}{|c|}{ Three } & \multicolumn{2}{|c|}{ Four } & \multicolumn{2}{|c|}{ Total } & \\
\hline & No. & (\%) & No. & (\%) & No. & (\%) & p \\
\hline Three & 20 & $(20.0)$ & 0 & $(0.0)$ & 20 & (19.8) & \\
\hline Four & 71 & (71.0) & 0 & $(0.0)$ & 71 & (70.3) & \\
\hline Five & 9 & (9.0) & 1 & $(100.0)$ & 10 & (9.9) & 0.099* \\
\hline Total & 100 & $(100.0)$ & 1 & $(100.0)$ & 101 & (100.0) & \\
\hline
\end{tabular}

*By Fisher's exact test 


\section{Discussion}

This study was done to assess the prevalence of second mesiobuccal canal of maxillary first molars by using cone beam computer tomographyfor Erbil citizens. And as we know that knowing the morphology of the root canals will help in detection, cleaning and obturating of all canals during root canal therapy. Many studies have examined root and canal morphologies using various methods such as sectioning, ${ }^{2}$ canal staining and tooth clearing, ${ }^{21}$ modified canal staining and clearing, ${ }^{7}$ in vitro endodontic access cavity with radiography and instruments, ${ }^{22}$ in vitro macroscopic examination, ${ }^{10}$ in vivo root canal therapy with magnification, ${ }^{17}$ conventional radiography techniques, ${ }^{23}$ contrast medium-enhanced radiography, ${ }^{24}$ and cone-beam computed tomography (CBCT) scanning. ${ }^{1}$ In comparison to modified canal staining and clearing technique, CBCT is more accurate in identifying root canal systems. ${ }^{4,25}$ For detection of the second mesiobuccal canal, the results showed that CBCT scanning is a reliable method compared to the gold standard (sectioning). ${ }^{26}$ Another study stated that microcomputed tomography $(\mu \mathrm{CT})$ of the canal counts were not different from CBCT results but significantly different from digital periapical radiographies in detection of the extra canals in the mesiobuccal roots of maxillary molars. ${ }^{27}$ The advantages of CBCT in comparison with $\mathrm{CT}$ are lower radiation dose, reduced exposure time, lower costs and higher accuracy. Furthermore, CBCT measurements are accurate, according to isotropic voxels. ${ }^{4}$ In comparison to modified canal staining and clearing technique, $\mathrm{CBCT}$ is accurate in identifying root canal systems. ${ }^{4,25}$

This study found that $80.2 \%$ of maxillary first molars among Erbil citizens has second mesiobuccal canals. This result was highly consistent with findings in Irish population $(80.4 \%){ }^{28}$ and closely consistent with Italy $(80 \%) .{ }^{29}$ But higher than Korean $(70.5 \%),{ }^{30}$ North American population $(68.2 \%),{ }^{31}$ and China $(52 \%){ }^{32}$ Whereas there is higher findings in a Barazilian study $(86.1 \%){ }^{33}$

\section{Conclusions}

The prevalence of MB2 in maxillary first molars in Erbil citizens is $80.2 \%$. By other words from 10 patients that they enter our clinic for root canal therapy in maxillary first molars suspect that 8 of them having additional mesiobuccal canals. That is why the dentists especially the general practitioners should be aware and take it as a hint that the possibility of having additional canals in maxillary first molars is high enough to be take it seriously and looked after it. Since one of the main causes of failure of root canal therapy of maxillary molars are missing canals due to its complex anatomy. CBCT found out to be very effective way in helping practitioner to make a proper investigation and management of this problem.

\section{Conflicts of interest}

The authors reported no conflicts of intersts.

\section{References}

1. Altunsoy, M., Ok, E., Nur, B. G., Aglarci, O. S., Gungor, E. \& Colak, M. Root canal morphology analysis of maxillary permanent first and second molars in a southeastern Turkish population using cone-beam computed tomography. J Dent Sci 2015; 10:401-407.

2. Weine, F. S., Healey, H. J., Gerstein, H. \& Evanson, L. Canal configuration in the mesiobuccal root of the maxillary first molar and its endodontic significance. Oral Surg Oral Med Oral Pathol 1969; 28:419-425.

3. Vertucci, F. J.. Root canal morphology and its relationship to endodontic procedures. Endod Topics 2005;10:3-29.

4. Neelakantan, P., Subbarao, C., Ahuja, R., Subbarao, C. V. \& Gutmann, J. L. Cone-beam computed tomography study of root and canal morphology of maxillary first and second molars in an Indian population. J Endod 2010; 36:16221627.

5. Silva, E. J. N. L., Nejaim, Y., Silva, A. I., Haiter-Neto, F., Zaia, A. A. \& Cohenca, N. Evaluation of root canal configuration of maxillary molars in a Brazilian population using cone-beam computed tomographic imaging: an in vivo study. J Endod 2014; 40:173-176. 
6. Chen, G., Yao, H. \& Tong, C. Investigation of the root canal configuration of mandibular first molars in a Taiwan Chinese population. Int Endod J 2009; 42:1044-1049.

7. Weng, X.-L., Yu, S.-B., Zhao, S.-L., Wang, H.-G., Mu, T., Tang, R.-Y. \& Zhou, X.-D. Root canal morphology of permanent maxillary teeth in the Han nationality in Chinese Guanzhong area: A new modified root canal staining technique. J Endod 2009; 35:651-656.

8. Kontakiotis, E. G. \& Tzanetakis, G. N. Four canals in the mesial root of a mandibular first molar. A case report under the operating microscope. Aust Endod J 2007; 33:84-88.

9. Cheung, G. Endodontic failures-changing the approach. Int Dent J 1996; 46:131-138.

10. Pecora, J. D., Woelfel, J. B., Sousa Neto, M. \& Issa, E. P. Morphologic study of the maxillary molars. Part II: Internal anatomy. Braz Dent J 1992; 3:53-7.

11. Sert, S. \& Bayirli, G. S. Evaluation of the root canal configurations of the mandibular and maxillary permanent teeth by gender in the Turkish population. J Endod 2004; 30:391-398.

12. Cleghorn, B. M., Christie, W. H. \& Dong, C. C. Root and root canal morphology of the human permanent maxillary first molar: A literature review. JEndod 2006; 32:813-821.

13. Pomeranz, H. H. \& Fishelberg, G. The secondary mesiobuccal canal of maxillary molars. J Am Dent Assoc. 1974; 88:119-124.

14. Hartwell, G. \& Bellizzi, R. Clinical investigation of in vivo endodontically treated mandibular and maxillary molars. J Endod 1982; 8:555-557.

15. Hess, W., Zürcher, E. \& Dolamore, WH. The anatomy of the root-canals of the teeth of the permanent dentition. London: J. Bale, Sons \& Danielsson, Ltd.; 1925.

16. Vertucci FG, Haddix JE, Britto LR. Tooth morphology and access cavity preparation. In: Cohen S, Hargreaves KM, editors. Pathways of the Pulp. $9^{\text {th }}$ ed. Mosby, St Louis, Missouri, USA. 2006. p. 148-232.

17. Buhrley, L. J., Barrows, M. J., Begole, E. A. \& Wenckus, C. S. Effect of magnification on locating the mb2 canal in maxillary molars. J Endod 2002; 28:324-327.

18. Peeters, H. H., Suardita, K. \& Setijanto, D. Prevalence of a second canal in the mesiobuccal root of permanent maxillary first molars from an indonesian population. J Oral Sci 2011; 53:489494.

19. Betancourt P, Navarro P, Cantín M, Fuentes R. Cone-beam computed tomography study of prevalence and location of MB2 canal in the mesiobuccal root of the maxillary second molar. Int J Clin Exp Med. 2015;8:9128-34

20. Wang, H., Ci, B.-W., Yu, H.-Y., Qin, W., Yan, Y.-X., $\mathrm{Wu}$, B.-L. \& Ma, D.-D. Evaluation of root and canal morphology of maxillary molars in a southern Chinese subpopulation: A cone-beam computed tomographic study. Int J Clin Exp Med 2017; 10:7030-7039.

21. Asgary, S., Eghbal, M. J. \& Parirokh, M. 2008. Sealing ability of a novel endodontic cement as a root-end filling material. J Biomed Mater Res A 2008; 87:706-709.

22. Kulid, J. C. \& Peters, D. D. 1990. Incidence and configuration of canal systems in the mesiobuccal root of maxillary first and second molars. J Endod 1990; 16:311-317.

23. Pineda, F. \& Kuttler, Y. Mesiodistal and buccolingual roentgenographic investigation of 7,275 root canals. Oral Surg Oral Med Oral Pathol 1972; 33:101-110.

24. Fernandes, M., De Ataide, I. \& Wagle, R. Cshaped root canal configuration: A review of literature. J Conserv Dent 2014; 17:312.

25. Velmurugan, N. \& Sandhya, R. Root canal morphology of mandibular first premolars in an indian population: a laboratory study. Int Endod J 2009; 42:54-58.

26. Blattner, T. C., George, N., Lee, C. C., Kumar, V. \& Yelton, C. D. Efficacy of cone-beam computed tomography as a modality to accurately identify the presence of second mesiobuccal canals in maxillary first and second molars: a pilot study. J Endod 2010; 36:867-870.

27. Domark, J. D., Hatton, J. F., Benison, R. P. \& Hildebolt, C. F. An ex vivo comparison of digital radiography and cone-beam and micro computed tomography in the detection of the number of canals in the mesiobuccal roots of maxillary molars. J Endod 2013; 39:901-905.

28. Al Shalabi, R., Omer, J. G., Jennings, M. \& Claffey, N. Root canal anatomy of maxillary first and second permanent molars. Int Endod J 2000; 33:405-414.

29. Somma, F., Leoni, D., Plotino, G., Grande, N. \& Plasschaert, A. Root canal morphology of the mesiobuccal root of maxillary first molars: a micro-computed tomographic analysis. Int Endod J 2009; 42:165-174.

30. Kim, Y., Lee, S.-J. \& Woo, J. Morphology of maxillary first and second molars analyzed by cone-beam computed tomography in a Korean population: variations in the number of roots and canals and the incidence of fusion. J Endod 2012; 38:1063-1068.

31. Guo, J., Vahidnia, A., Sedghizadeh, P. \& Enciso, R. Evaluation of root and canal morphology of 
maxillary permanent first molars in a North American population by cone-beam computed tomography. J Endod 2014; 40:635-639.

32. Zhang, R., Yang, H., Yu, X., Wang, H., Hu, T. \& Dummer, P. M. H. Use of CBCT to identify the morphology of maxillary permanent molar teeth in a Chinese subpopulation. Int Endod J 2011; 44:162-169.

33. Reis, A. G. D. A. R., Grazziotin-Soares, R., Barletta, F. B., Fontanella, V. R. C. \& Mahl, C. R. W. Second canal in mesiobuccal root of maxillary molars is correlated with root third and patient age: A cone-beam computed tomographic study. J 